\title{
Relações de produção em indústrias criativas: trabalho, consumo cultural e sustentação identitária em editoras infantojuvenis
}

\author{
Productive relations in creative industries: work, cultural consumption and identity support \\ in publishing companies
}

Isabel de Sá Affonso da Costa ${ }^{1}$

Pedro Xavier Borges ${ }^{2}$

Jorge Augusto de Sá Brito e Freitas ${ }^{3}$

\begin{abstract}
Resumo
Este artigo apresenta resultados de uma pesquisa que objetivou analisar as relações de trabalho em organizações de uma indústria criativa: as editoras voltadas para o público infantojuvenil. As relações de trabalho referem-se a questões organizativas e a relações pessoais com o trabalho. Para tal estudo, foi realizada pesquisa exploratória, com evidências de cunho qualitativo, relativas a seis editoras sediadas nos estados de Minas Gerais, Rio de Janeiro e São Paulo. Os dados foram analisados de forma interpretativa, recorrendo-se à triangulação de evidências, a partir das seguintes fontes: i) entrevistas em profundidade, realizadas com os seis respectivos editores responsáveis; ii) observação direta nas editoras e iii) consultas a sites de comunidades de consumidores ligados aos produtos dessas editoras. Os resultados indicam que as práticas de gestão adotadas envolvem não só flexibilidade organizativa, mas, principalmente, um entendimento ampliado do processo de produção e de consumo do bem cultural (livro), que passa pela integração de editores, autores e consumidores, via formação de comunidades virtuais atuando de forma simbiótica. Nessa relação, as editoras buscam sobrevivência e viabilidade comercial, enquanto os consumidores buscam sustentação identitária - o que os leva a se envolver no processo produtivo sem visar compensação financeira, mas retornos de ordem subjetiva, constituindo força de trabalho não remunerada para as editoras.
\end{abstract}

Palavras-chave: indústrias criativas; editoras; relações de trabalho; comunidades virtuais; teletrabalho.

Artigo submetido em maio de 2010 e aceito para publicação em setembro de 2010.

1 Doutora em Administração pela Fundação Getúlio Vargas/EBAPE; Professora do Programa de Mestrado em Administração e Desenvolvimento Empresarial da Universidade Estácio de Sá (MADE/UNESA). Endereço: Universidade Estácio de Sá - Mestrado em Administração e Desenvolvimento Empresarial, Av. Presidente Vargas, 642, 22ํ․ andar, Centro, CEP 20071-001, Rio de Janeiro, RJ, Brasil. E-mail: isabel.costa@estacio.br

Mestre em Administração e Desenvolvimento Empresarial pela Universidade Estácio de Sá/MADE. Endereço: Universidade Estácio de Sá - Mestrado em Administração e Desenvolvimento Empresarial, Av. Presidente Vargas, 642, 22‥ andar, Centro, CEP 20071001, Rio de Janeiro, RJ, Brasil. E-mail: pxborges@terra.com.br

3

Doutor em Administração de Empresas pela Pontifícia Universidade Católica do Rio de Janeiro/IAG; Mestre em Administração e Desenvolvimento Empresarial pela Universidade Estácio de Sá/MADE; Professor da Universidade Estácio de Sá (MADE/UNESA). Endereço: Universidade Estácio de Sá - Mestrado em Administração e Desenvolvimento Empresarial, Av. Presidente Vargas, 642, 22‥ andar, Centro, CEP 20071-001, Rio de Janeiro, RJ, Brasil. E-mail: jasbfreitas@globo.com 


\begin{abstract}
This paper presents results of a study that aimed to explore work relations in a creative industry: children's and young adult literature publishing companies. Work relations refer to organizing practices and individual attitudes towards work. To achieve the research goals, an exploratory approach was adopted and qualitative evidence was gathered concerning six publishing companies located in Minas Gerais, Rio de Janeiro and São Paulo. Data were analyzed in an interpretive way, through evidence triangulation collected from the following sources: i) in-depth interviews with the six editors-inchief; ii) direct observation at the publishing companies; iii) websites of virtual communities of consumers interested in the publishing companies' products. The results indicate that managerial practices adopted by the publishing companies embrace organizing flexibility and, more significantly, that publishers have an extended understanding of the production and consumption processes of their cultural goods (books) that encompasses the integration of editors, authors and consumers in virtual communities of practice. In this relationship, the publishing companies pursue economic viability, while consumers pursue identity support - and that lead consumers adhere to the production process seeking only subjective compensations, thus transforming themselves into an unpaid workforce for the companies.
\end{abstract}

Keywords: creative industries; publishing companies; work relations; virtual communities; telework.

\title{
Introdução
}

Indústrias criativas podem ser entendidas como aquelas em que a criatividade é elemento central do negócio, sendo esta percebida como necessária para a geração de propriedade intelectual (BENDASSOLI et al, 2009). Isso é dizer que, nas indústrias criativas, a criatividade, em última instância, traduz-se em valor para o mercado. As indústrias criativas englobam atividades econômicas novas e outras mais antigas, tais como: cinema, design, indústria editorial, indústria fonográfica, moda e software. Como destaca Jaguaribe (2004), o que essas atividades econômicas têm em comum é o fato de todas estarem centradas na produção de textos, imagens e símbolos.

A importância das indústrias criativas é um fenômeno associado à passagem da sociedade industrial para a sociedade pós-industrial. Está relacionada a mudanças econômicas, tecnológicas e produtivas que fazem do conhecimento elemento-chave da competitividade econômica, trazendo ambiguidade, complexidade e incerteza em lugar da padronização e da previsibilidade características do taylorismo-fordismo. Também está relacionada a transformações culturais profundas, relativas à ascensão do indivíduo e dos valores individualistas como referência da vida social e à estetização da vida cotidiana pela via do consumo (FLORIDA, 2004; HASEMAN, 2005; HARVEY, 2003).

As indústrias criativas estão centradas na produção de bens imateriais, cujo consumo possui caráter cultural (BENDASSOLLI et al, 2009). Bens culturais têm natureza não utilitária - ou seja, geram experiências, mais do que utilidade - e seu valor vem dessas experiências de natureza subjetiva (LAMPEL; LANT; SHAMSIE, 2009). Devido à imprevisibilidade inevitável dessas experiências, as organizações dessas indústrias precisam apoiar-se em formas de organização capazes de lidar com a incerteza e com o equilíbrio entre tendências opostas. À medida que os componentes de ambiguidade, complexidade e imprevisibilidade começam a tornar-se foco de atenção para outros setores produtivos, a experiência acumulada pelas organizações das indústrias criativas ganha relevância como objeto de estudo na área de gestão.

As editoras figuram entre as indústrias criativas mais antigas, fundadas sobre uma das mais significativas inovações tecnológicas da história: a invenção dos tipos móveis por Gutenberg. Contemporaneamente, as tecnologias de informação e comunicação (TICs) têm atuado para transformar processos produtivos, possibilitar a incorporação de novos recursos e competências, abrir novos canais de distribuição e aumentar o escopo de atuação das editoras, descortinando novas possibilidades para o mercado editorial. 
No Brasil, as mudanças no mercado editorial, derivadas da massificação das TICs, não são desprezíveis. Processos de produção foram barateados, novas editoras surgiram, pequenas tiragens tornaram-se comercialmente viáveis, estratégias de exploração de nichos de mercado tornaram-se acessíveis, trazendo como resultado grande variedade de títulos de livros e revistas nas livrarias e bancas de jornal de todo o país. Cabe explorar, na peculiaridade de organizações das indústrias criativas, as estratégias gerenciais que subjazem a essas transformações.

Este estudo buscou explorar as relações de trabalho presentes nas editoras voltadas para o público infantojuvenil. As relações de trabalho referem-se a questões organizativas e a relações pessoais com o trabalho. O interesse principal pelas editoras se deve ao fato de elas há muito se apoiarem numa prática de organização do trabalho que, para diversos setores, é recente: o trabalho a distância, contratado sob demanda para a produção de determinado produto (livro). Ao mesmo tempo, por seus recursos críticos estarem incorporados a indivíduos, sobre os quais podem exercer controle limitado, o sucesso depende, em última instância, da intensidade e qualidade do envolvimento dos participantes no projeto, exigindo uma relação significativa com o trabalho. Foi realizada pesquisa exploratória, com evidências qualitativas obtidas através de entrevistas realizadas com seis editores responsáveis por editoras em Minas Gerais, no Rio de Janeiro e em São Paulo. Os dados foram tratados analiticamente pela triangulação de evidências coletadas nas entrevistas, em observação direta nas editoras e por consultas a sites de comunidades de consumidores ligados aos produtos dessas mesmas editoras. Os resultados revelam que as práticas de gestão adequadas envolvem não só flexibilidade organizativa, mas principalmente um entendimento ampliado do processo de produção e de consumo do bem cultural (livro), que passa pela integração de editores, autores e consumidores via formação de comunidades virtuais.

\section{Indústrias culturais e indústrias criativas}

Segundo a Unesco (2006), o termo indústria cultural refere-se às indústrias que combinam a criação, produção e comercialização de conteúdos criativos que são intangíveis e de natureza cultural. Os conteúdos costumam ser protegidos por direitos autorais e os produtos podem ser bens ou serviços. Já as indústrias criativas são aquelas cujos produtos ou serviços contêm um elemento substancial de esforço criativo ou cultural. O termo engloba uma gama maior de atividades: inclui as indústrias culturais, além de toda produção artística e cultural - "seja ao vivo ou produzida como unidade individual" (UNESCO, 2006, p.3, tradução livre). Toda indústria cultural pode ser considerada, então, uma indústria criativa.

Lampel, Lant e Shamsie (2009) sustentam que a principal característica das indústrias culturais deriva do caráter não utilitário dos produtos gerados. No que diz respeito aos bens utilitários, como o nome sugere, a utilidade define as características do produto, gerando atributos mais ou menos estáveis que, uma vez a eles incorporados, permitem julgamento acerca de sua qualidade. Quantos aos bens culturais, estes não têm utilidade a priori e seu valor deriva da experiência subjetiva que geram; seus padrões de qualidade representam ideais abstratos e não, padrões específicos, derivados de atributos de adequação ou desempenho. Atributos tais como "originalidade" ou "ousadia" podem ser identificados como relevantes para a percepção da qualidade de determinado bem cultural ou do valor da experiência por ele produzida, mas o significado desses atributos pode ser radicalmente diferente para cada consumidor. Ao mesmo tempo, padrões estéticos e comportamentais encontram-se enraizados em uma matriz cultural e social ampla, sobre a qual as organizações da indústria cultural têm influência limitada.

O consumo dos produtos das indústrias criativas é marcado por seu caráter cultural (BENDASSOLLI et al, 2009). O consumo dos símbolos, textos e imagens serve a um regime de construção de identidades via consumo: o consumo não mais se limita a suprir necessidades ou a prover utilidade; pelo consumo se afirmam estilos de vida, segmentam-se grupos, exprimem-se valores. 
Para os gestores, esse terreno ambíguo implica que a sistematização do conhecimento pouco informa sobre o futuro, e tomar como base experiências passadas bem-sucedidas não é garantia de que o sucesso se repetirá. Como consequência, as decisões precisam apoiar-se mais em interpretação e conhecimento tácito do que em análises sistemáticas e conhecimento explícito. A forma de navegar nesse ambiente incerto se dá em duas vertentes (LAMPEL et al, 2009): do lado da demanda, as organizações tentam moldar as preferências do consumidor via novos métodos de distribuição, de comercialização e de produção; do lado da oferta, as organizações buscam desenvolver formas de gerenciar adequadamente os recursos criativos, equilibrando os imperativos de liberdade criativa e os imperativos comerciais. Para os autores, essas características esboçam, para as organizações da indústria cultural, um campo de ação definido por cinco polaridades: valores artísticos versus entretenimento de massa; diferenciação de produtos versus inovação de mercado; análise da demanda versus construção de mercado; integração vertical versus especialização flexível; e inspiração individual versus sistemas criativos.

Bendassolli et al (2009) apontam que a forma de produção das indústrias criativas apresenta quatro características: a criatividade como recurso-chave; a valorização da arte pela arte; o fomento ao uso intensivo de novas tecnologias; e a formação de equipes polivalentes.

A forma de produção das indústrias criativas tem como primeira característica a criatividade - em última instância, a sobrevivência das organizações da indústria criativa depende do sucesso em gerenciar e renovar os recursos criativos. Assim, se indivíduos ou pequenos grupos concebem e desenvolvem os produtos criativos, é preciso desenvolver estruturas e processos organizacionais capazes de alavancar esses recursos e garantir sua continuidade.

A valorização da arte pela arte (CAVES, 2000), ou a relevância dos valores artísticos (LAMPEL; LANT; SHAMSIE et al, 2009) como traço distintivo das indústrias criativas, é a segunda característica da forma de produção dessas indústrias. Nas organizações da indústria criativa, valores artísticos e estéticos têm grande influência sobre as escolhas estratégicas e relativas à alocação de recursos. No entanto, como essas organizações precisam atender também aos imperativos de mercado, esses valores quase sempre estão em estado de tensão ou mesmo de conflito aberto com os princípios de racionalidade que guiam escolhas instrumentais nessas organizações.

O uso intensivo de novas tecnologias, especialmente as TICs, permite a pulverização das atividades criativas. Pequenas empresas ou comunidades de produtores podem disseminar suas criações, diminuindo o poder de organizações de grande porte em determinados campos. Isso, associado ao fato dos produtos das indústrias criativas serem de consumo cultural, estimula o surgimento de comunidades de consumidores que compartilham valores associados (geralmente via publicidade) aos produtos.

A quarta característica da forma de produção das indústrias criativas é o uso extensivo de equipes polivalentes. Isso se deve ao fato do processo produtivo exigir a conjugação de conhecimentos e recursos diversos ao longo de seu desenvolvimento. Não se trata de organizar matricialmente ou por projetos uma estrutura funcional; "nas indústrias criativas a polivalência é intrínseca à própria organização" (BENDASSOLLI et al, 2009, p.13).

Robinson (2005) acredita existir uma crise de inventividade, uma guerra por talentos que dirige a atenção para as práticas das indústrias criativas: a) uma sinergia criativa poderosa surge quando profissionais de diferentes áreas trabalham juntos; b) cenários criativos criam oportunidades para experimentar, falhar, tentar de novo, perguntar, descobrir e criar conexões com elementos aparentemente díspares, que mesmo que não levem a um produto criativo ou a uma aplicação científica, mostram que ambiente propício é essencial para o processo criativo; e c) a criatividade é um atributo humano que precisa ser desenvolvido, especialmente, quando percebemos os frutos do seu estímulo, como, por exemplo, nos estudos.

Cada vertente das indústrias criativas possui uma gama de intermediários próprios, chamados por Caves (2000) de gatekeepers, que selecionam e decidem quais artistas podem ter uma chance de entrar no mercado. 
Sua tradução literal, guardiões do portal, passa exatamente a ideia de que apenas poucos indivíduos podem participar desse universo fechado. No ramo editorial, os gatekeepers são os editores, que tradicionalmente recebem diversas ofertas de novos autores iniciantes, escolhendo às vezes um ou dois para trabalhar. Entretanto, com a facilitação e o barateamento dos custos de produção de livros e revistas, o seleto grupo dos autores se transformou num lugar muito mais acessível.

No mercado editorial, o impacto da disseminação das TICs pode ser percebido pela pulverização e especialização das editoras em determinados segmentos. Motivadas pela forma como o processo produtivo de uma publicação foi facilitado - em parte, graças aos softwares de edição e à evolução dos parques gráficos -, novas editoras surgiram com o interesse de atender a uma demanda existente por produtos nacionais, mais baratos e voltados para públicos específicos. Os avanços da tecnologia e a melhora nos processos de distribuição e controle permitiram o surgimento das chamadas gráficas de microtiragens. Com a popularização da internet, as editoras começaram a explorar novos canais de comunicação, tanto com o seu público quanto com consumidores em potencial, a um custo baixo ou próximo de zero. A distribuição via sites das próprias editoras contrabalançou a tendência de concentração dos canais de distribuição, especialmente livrarias. Desde o final dos anos 1980, a variedade de títulos de livros e revistas cresceu significativamente nas prateleiras de livrarias e, especialmente, das bancas de jornal do País. ${ }^{i}$

\section{O processo de produção em editoras: equipes polivalentes}

As responsabilidades de um editor se concentram essencialmente em três funções: criação da publicação, produção gráfica e distribuição.

Na criação de uma publicação, o editor lida com escritores, ilustradores e fotógrafos. A compilação do trabalho deve, ainda, ser feita por um diagramador e corrigida por um revisor - atividades que costumam ser acumuladas pelo editor nas empresas menores ou quando há necessidade de algum cuidado especial.

Tradicionalmente, os autores ganham uma porcentagem sobre as vendas dos livros. Escritores e editores relacionam-se como parceiros investidores e quem faz o maior investimento (especialmente financeiro) detém uma maior parcela dos lucros. Como normalmente um autor contribui somente com o seu trabalho na fase de criação, é comum que as editoras ofereçam aos escritores pouco conhecidos ou desconhecidos apenas $10 \%$ do preço de capa da publicação ou, em alguns casos, do valor recebido das livrarias com desconto em vendas antecipadas, ou seja, sem consignação. À medida que o autor/artista tiver seu trabalho reconhecido, mais condições ele terá de pedir uma participação maior nesses lucros.

Ilustradores e fotógrafos cobram por imagens e o valor pago varia muito, caso se trate de iniciantes ou de profissionais mais experientes. $\mathrm{O}$ melhor custo/benefício para a editora depende muito mais dos contatos do editor do que da capacidade de investimento da empresa.

Tendo em vista a disseminação dos softwares de correção ortográfica, atualmente, os revisores buscam oferecer mais serviços do que simplesmente corrigir textos, como sugerir substituições em trechos confusos ou especialização nos termos técnicos de alguma área de conhecimento. Não foi possível, porém, impedir que o custo dessa mão-de-obra se desvalorizasse muito desde a segunda metade dos anos 1990. Mais uma vez, a capacidade do editor de encontrar um custo/benefício satisfatório para cada projeto pode trazer diferenças significativas nos lucros da editora, tornando bastante comum a contratação de autônomos.

$\mathrm{Na}$ diagramação, é mais difícil encontrar mão de obra especializada, especialmente, quando é preciso administrar uma identidade visual numa publicação repleta de fotos e ilustrações. Essa atividade costuma ser executada pelo próprio editor ou por alguém de sua confiança, principalmente, nas empresas menores. É difícil encontrar bons diagramadores autônomos, pois eles tendem a ser contratados pelas editoras. 
Uma das principais atribuições de um editor, além dos contatos de trabalho mencionados anteriormente, é garantir a harmonia dos trabalhos realizados para a publicação - entre textos, imagens, fotos, diagramação etc. - formando assim a identidade do produto.

Durante a produção gráfica, o editor precisa do auxílio de um especialista, mesmo que ele pertença à empresa com quem a editora terceiriza a impressão. Ainda que apenas as grandes editoras possuam suas próprias gráficas, nada impede que deleguem essa função a outras companhias, sendo comum contratar no exterior para baratear essa etapa do processo produtivo. Como a maioria das publicações brasileiras utiliza arquivos de software como o Adobe Page Maker ou Adobe In Design, esses programas se tornaram essenciais para as gráficas. Atualmente, qualquer um deles pode ser instalado e utilizado sem dificuldade por um computador pessoal com uma configuração mínima de hardware, encontrado facilmente até mesmo nos modelos mais econômicos. Portanto, qualquer editor ou autor pode mandar por e-mail a versão finalizada de uma obra para qualquer parte do mundo, a ponto de diversas empresas grandes "rodarem" suas publicações fora de seus estados ou do país para baratear seus custos de produção.

Como nos anos 1980 e início da década de 1990 não havia um número suficiente de gráficas para atender à demanda, era considerado um importante diferencial possuir uma gráfica própria dentro da editora, especialmente, quando se trabalhava com grandes tiragens. No entanto, junto com a evolução tecnológica, esse mercado não apenas cresceu como se diversificou, permitindo aos editores conseguirem preços competitivos sem ter de depender da disponibilidade das gráficas. Os editores tendem a ser fiéis às gráficas que atendem às suas expectativas, sendo comum que haja longas relações entre essas empresas.

Uma vez pronta a publicação, tem início a parte do processo onde o editor precisa garantir o melhor retorno financeiro da venda direta. Tradicionalmente, os pontos de venda menores cobram $30 \%$ do preço de capa, como as livrarias isoladas. No entanto, esses descontos podem chegar a cerca de $60 \%$, como nas grandes redes que possuem seus próprios sistemas de distribuição nacional e costumam comprar alguns volumes para aumentar essa porcentagem, ao invés de tomarem por consignação. Mesmo que os editores prefiram um contato direto com as livrarias para garantir um desconto menor, o auxílio das distribuidoras que terceirizam esse serviço se torna obrigatório para quem deseja ampliar sua distribuição por todo o território nacional. No caso das bancas de jornal, a distribuição nacional passou, em 2007, a ser controlada por apenas uma empresa, que costuma cobrar cerca de $50 \%$ e não aceita menos de 5.000 unidades para viabilizar a distribuição entre as milhares de bancas do país, ou 3.000 com distribuição setorizada (quando são espalhadas num estado e recolhidas um mês depois, para serem redistribuídas em outro).

\section{Organização do trabalho: teletrabalho}

A organização do trabalho em uma editora caracteriza-se pelo emprego extensivo de autônomos, contratados sob demanda, que contribuem com suas competências ao processo de produção de determinada publicação. Quanto menor a editora, mais se pode esperar que não conte com empregados fixos, valendo-se de autônomos ou terceirizando partes do processo produtivo. Com a disseminação das TICs, as editoras tornaram-se exemplo de uso intensivo de teletrabalho.

Qvortup (1992) distingue três modalidades de teletrabalhadores: 1) substituidores - os que trocam o serviço efetuado no ambiente de trabalho comum pelo serviço em casa; 2) autônomos - trabalhando on-line de suas casas e 3) complementadores - que levam para casa uma parte do trabalho a ser completado fora do escritório, trabalho complementar esse que, em alguns casos, como acontece com pesquisadores, representa a maior parte da carga de trabalho. Esta pesquisa trata exclusivamente da modalidade autônoma do teletrabalho, por ser esta a que caracteriza o mercado editorial. Nessa modalidade podem ser encontrados trabalhadores temporários, ainda em fase de formação e muitas vezes mal pagos, bem como autônomos que 
obtêm ganhos financeiros consideráveis graças a um talento ou formação bem acima da média, como é o caso dos escritores renomados.

A implantação do teletrabalho pode trazer uma série de benefícios às organizações, já amplamente apontados na literatura (COSTA, 2003; DOHERTY; ANDREY; JOHNSON, 2000; NILLES, 1994; TROPE, 1999), tais como:

- possibilidade da empresa funcionar 24 horas/7 dias por semana;

- maior flexibilidade organizacional, que permite empregar pessoas que normalmente estariam inacessíveis pela distância geográfica;

- possibilidade de manter contato com um número maior e mais diversificado de profissionais habilitados a prestar serviços, permitindo ampliar o escopo de produção sem arcar com os custos de manutenção das competências na empresa;

- redução dos custos imobiliários, de manutenção do escritório e de transporte;

- integração de funcionários e/ou parceiros que não se enquadrariam na realidade do espaço de trabalho ou que poderiam ter dificuldades para interagir; e

- menor rotatividade de trabalhadores que, por alguma razão, precisam mudar de moradia.

No caso de teletrabalhadores autônomos, some-se a essas vantagens o fato de que os custos trabalhistas são muito reduzidos e o trabalho é realizado sob demanda.

No que tange às desvantagens do teletrabalho, a teoria e os estudos de campo apontam que elas se concentram no lado do teletrabalhador, especialmente no tocante a sua vida familiar, às jornadas extensas e a questionamentos quanto às possibilidades de ascensão na carreira - preocupações que passam ao largo da organização, no caso dos autônomos. Já as desvantagens para as organizações são pouco significativas, particularmente, quando comparadas aos enormes ganhos que o teletrabalho pode representar. No que concerne aos autônomos, pode se antecipar que os pontos críticos da gestão de mão de obra referem-se a possíveis falhas na "entrega" do serviço, seja em relação a prazos quanto à própria qualidade do serviço prestado. Tal risco não deve ser desprezado, uma vez que parte significativa do processo produtivo envolve trabalho para o qual pode não haver fácil substituição.

Mais do que isso, como alguns estudos têm apontado (COSTA, 2007; PUMA; WETZEL, 2007), o teletrabalho envolve a transformação do sentido do trabalho, a construção de novas subjetividades e um novo relacionamento com o trabalho. Quanto aos teletrabalhadores que mantêm vínculos empregatícios com as organizações para as quais (tele)trabalham, esse novo relacionamento constrói-se sobre a lógica dos discursos do profissionalismo e do empreendedorismo de si (COSTA, 2007). No caso da produção de livros, no entanto, a relação com o trabalho parece sustentar-se sobre aspectos que vão além das questões de responsabilização, comprometimento e desempenho: diz respeito igualmente a aspectos afetivos e de estilos de vida.

\section{Relações de produção em rede: comunidades de prática}

Um efeito do uso intensivo das TICs pelas editoras é o envolvimento direto e crescente do público com o produto por elas oferecido. Com as várias comunidades de relacionamento da internet, fãs de todos os cantos do país e do mundo possuem agora um importante canal de comunicação com as empresas. Esses aficionados dispõem, especialmente, de um canal de comunicação entre eles mesmos, o que pode contribuir 
tanto para o aprimoramento dos produtos conforme a demanda quanto para a migração desse consumidor para um produto similar que atenda as suas reivindicações, se ignoradas. Um dos reflexos disso é a contratação ou o envolvimento desse consumidor, por parte da empresa, para a elaboração e o desenvolvimento de livros, revistas, jogos, filmes etc.

O significado original de comunidade não denota um espaço definido por fronteiras, mas o compartilhar de recursos (WENGER; McDERMOTT; SNYDER, 2002). O termo costuma evocar conotações emotivas, usado sempre de maneira positiva, com ideias implícitas de camaradagem, coesão, comunhão e relações horizontais, mesmo sendo tênues os laços. "O que une uma comunidade não é a sua estrutura, mas um estado de espírito - um sentimento de comunidade" (OUTWAITE; BOTTOMORE, 1996, p.116).

Comunidades são vistas como configurações sociais nas quais os empreendimentos de seus integrantes são valorizados e sua participação é reconhecida como competência; ou seja, quem pertence à comunidade é competente para ter acesso ao seu repertório e usá-lo de maneira considerada adequada (WENGER, 1998). As comunidades caracterizam-se por práticas específicas que definem limites de pertencimento e identidades (WENGER; McDERMOTT; SNYDER, 2002).

O termo comunidade de prática surgiu a partir do aparecimento do termo comunidades de aprendizado, onde a capacidade e a velocidade do aprendizado coletivo das pessoas formam a verdadeira vantagem competitiva sustentável (SENGE, 2001). No entanto, nem toda comunidade define-se pelas práticas que compartilha, assim como nem toda prática está inserida no âmbito de uma comunidade específica. Um bairro pode ser chamado de comunidade, mas não se constitui necessariamente em comunidade de prática (WENGER, 1998). Nas comunidades de prática, as pessoas são ligadas pelo envolvimento concreto em atividades comuns, engajadas mutuamente num empreendimento coletivo, orientadas por um senso de propósito comum (KIMBLE; HILDRETH, 2004). Uma comunidade de prática não se reduz a propósitos instrumentais, pois se refere não apenas a conhecer, mas também ao membros estarem juntos, dando significado às ações de cada membro, desenvolvendo identidade (WENGER, 1998).

Há três dimensões de relações pelas quais a prática é a fonte de coerência de uma comunidade: engajamento mútuo, empreendimento conjunto e repertório compartilhado. $\mathrm{O}$ engajamento mútuo envolve as competências de cada membro, o que cada um sabe, o que faz, bem como a habilidade que possui para conectar-se ao que não sabe e não faz, ou seja, ao conhecimento e às ações complementares dos demais membros. Pode haver competências que se sobrepõem, mas não significa que exista homogeneidade entre os membros, pois esta não é requisito nem resultado de uma comunidade de prática. O que torna o engajamento possível é muito mais uma questão de diversidade. Cada participante de uma comunidade de prática encontra espaço único dentro dela e possui uma identidade única, que se torna mais integrada e mais definida no curso do engajamento na prática. As identidades dos diversos membros vão se tornando cada vez mais articuladas, mas não se fundem umas às outras. Relações mútuas de engajamento forjam, ao mesmo tempo, diferenciação e homogeneização (WENGER, 1998).

O empreendimento conjunto de uma comunidade de prática é definido pelos participantes no próprio processo de sua constituição. Não é exatamente um objetivo estabelecido ou uma declaração de propósito definido no começo e perseguido por todos. Não é um acordo estático, mas um processo contínuo que vai definindo o que aquelas pessoas estão fazendo juntas. Essa negociação ocorre tanto de maneira explícita quanto implícita. É uma resposta negociada no conjunto de uma situação e que pertence aos participantes num sentido profundo, a despeito de todas as forças e influências que estejam além do controle destes. A definição do empreendimento cria um sentimento de compromisso comum que se torna parte integrante da prática, mesmo que não signifique que todos concordem sobre algo o tempo todo.

O repertório compartilhado de práticas inclui símbolos, rotinas, palavras, ações, conceitos, artefatos, maneiras de fazer certas coisas e gestos, os quais foram produzidos ou incorporados pela comunidade ao longo de sua trajetória. O repertório reflete uma história de mútuo engajamento e permanece sempre um 
tanto ambíguo, o que permite ressignificações e aplicação contínua, em diferentes situações. A ambiguidade não implica limites quanto ao significado, mas evidencia as diferentes maneiras pelas quais se pode continuamente atribuir significado a uma história (WENGER, 1998).

Entre os possíveis indicadores de que uma comunidade de prática se formou estão:

- relações mútuas sustentadas;

- identidades definidas mutuamente;

- maneiras compartilhadas de engajamento para fazer coisas juntos;

- habilidade para acessar de maneira apropriada ações e produtos;

- rápido fluxo de informações e de propagação de inovações;

- ferramentas, representações e outros artefatos específicos;

- ausência de comentários introdutórios, como se as conversas e interações fossem a continuação de um processo em curso;

- histórias locais compartilhadas, como piadas internas;

- rápida exposição de um problema a ser discutido;

- jargões e expressões na sua comunicação;

- coincidência substancial na descrição dos participantes;

- estilos reconhecidos de que alguém é membro da comunidade; e

- um discurso comum refletindo certa perspectiva de mundo.

Os elementos fundamentais nas comunidades de prática são a identidade, a participação e a reificação; ou seja, tratar uma abstração como substancialmente existente ou como um objeto material concreto (WENGER, 1998).

Por tratar comunidades de prática e comunidades virtuais como sinônimas, Teixeira Filho (2002) deixa de mencionar as possibilidades em que uma pode existir sem a outra, como um grupo de estudo que se encontra numa biblioteca ou um site que habitualmente reúne pessoas apenas para conversar pela internet. No entanto, comunidades virtuais se encaixam perfeitamente com o aprendizado coletivo e as comunidades de aprendizado e prática. Formadas por interesses comuns, por afinidades e preferências de consumo, essas comunidades têm sido usadas para adquirir um sentido contextual de identidade que enriquece a aprendizagem individual e organizacional, além de aumentar a motivação dos seus membros para aplicar o que aprendem (LESSER; STORCK, 2001).

Mediadas pelas TICs, autodeterminadas e orbitando muitas vezes em torno de um website, as comunidades virtuais apresentam a possibilidade de aflorar novas ideias para produtos e serviços, reduzindo retrabalho, evitando "reinvenção da roda" e dando uma resposta mais rápida às necessidades e indagações dos clientes/aficionados das indústrias culturais, dentro das características de sustentabilidade do consumo dos bens culturais.

As comunidades de prática consideradas neste estudo estão atreladas às comunidades virtuais e apresentam grande similitude com os cinco atributos das indústrias criativas, conforme indicados por Haseman (2005): envolvem interatividade; são intrinsecamente híbridas; envolvem novas formas de produção; contemplam meios de distribuição multiplataformas; e não descuram de uma possível relevância comercial. 
A comunidade virtual de prática não terá continuidade se os seus membros não forem participativos, se não se sentirem psicologicamente recompensados por essa participação e se as trocas ocorridas não reforçarem a paixão pelo que é feito (WENGER; McDERMOTT; SNYDER, 2002). As comunidades, como um organismo vivo, têm seu ciclo de vida: nascimento, crescimento, reprodução e, eventualmente, morte. Para um ciclo de vida rico em conhecimento e recompensador para os participantes, um dos fatores essenciais é a existência de uma cultura favorável à disseminação e ao compartilhamento de conhecimento (TEIXEIRA FILHO, 2002).

\section{Relações com o trabalho: ócio criativo}

Para os gregos, o ócio possuía uma conotação estritamente física: trabalho era tudo aquilo que fazia suar, com exceção do esporte e da guerra; quem suava e não era um atleta ou guerreiro, era escravo ou cidadão de segunda classe. As atividades não-físicas (a retórica, o estudo, a filosofia) eram funções "ociosas", ou seja, expressões mentais, dignas somente de cidadãos de primeira classe. Esse ócio, então, não estaria relacionado ao "não fazer nada", mas a não estar trabalhando no sentido físico da palavra, mesmo que ainda se mantendo ativo no campo das ideias, com o objetivo pautado pelo conhecimento.

Para De Masi $(1999,2000)$, na era pós-industrial, vamos aos poucos deixando os trabalhos físicos e repetitivos para as máquinas e começamos a nos voltar para o conhecimento e as ideias. Assim, deixamos gradualmente de ser uns "imbecis especializados", que nada sabem além do limitado treinamento profissional, uma vez que precisamos ser ensinados não mais a lidar com isto ou aquilo, mas a lidar com novos "istos ou aquilos", como se fôssemos naturalmente autodidatas, preparados para enfrentar cada vez mais novos desafios. Isso só é possível quando nos libertamos das amarras do trabalho mecânico e repetitivo. No auge da era industrial, se um operário permitisse que sua mente se perdesse em divagações, provavelmente, seu trabalho fosse prejudicado, comprometendo assim toda a linha de produção. Hoje, porém, diversos profissionais precisam ser

Graças aos novos meios de transporte e de comunicação, nossa sociedade se percebe, pela primeira vez, como uma aldeia global. De Masi (2000) prefere definir a sociedade pós-industrial colocando a criatividade no centro ao invés da programação, da organização obsessiva de todas as coisas feitas pelo homem. Com a era da globalização, o mundo não apenas ficou menor, mas extremamente parecido, isto porque tudo está mais acessível e uma convergência (não apenas na comunicação) se faz necessária para que possamos colher os frutos desse fenômeno.

De especial importância para esta pesquisa é o destaque dado à importância de se criar uma interseção entre trabalho-estudo-jogo e explorá-la. Essas três partes precisam estar interligadas de alguma forma para maximizar a capacidade de produção. Se um profissional possui um hobby, algo que lhe dê prazer e seja criativo e estimulante, não estará perdendo tempo durante o seu tempo livre. Não basta que o indivíduo faça um planejamento de acordo com seu desejo de ascensão, é preciso gostar de agir dessa forma.

Quanto à relação trabalho-estudo-jogo, De Masi (2000, p.147) assinala:

Quanto mais a natureza de um trabalho se limita à mera execução e implica puro esforço, mais ele se priva da dimensão cognoscitiva (área 2 do esquema abaixo) e da dimensão lúdica (área 3). Esta é a situação infeliz que no esquema corresponde à área 1. 


\section{Relação trabalho-estudo-jogo}

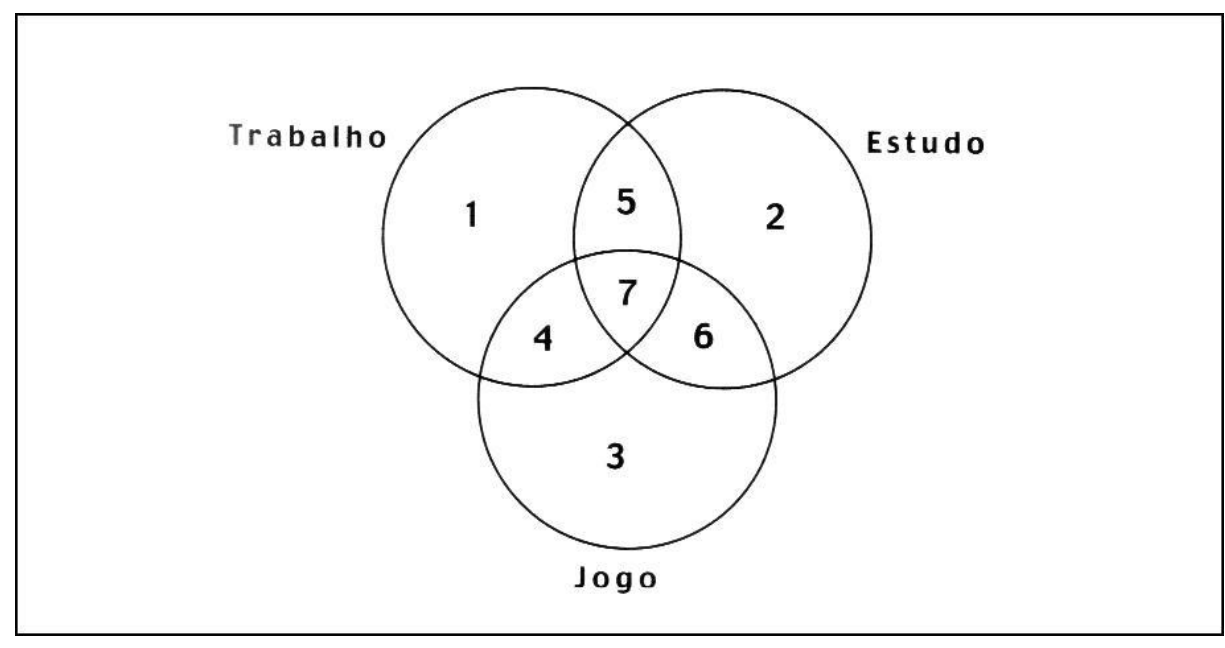

Fonte: De Masi (2000).

Existem, porém, trabalhos que desembocam no jogo, como, por exemplo, o de uma equipe cinematográfica que se diverte na filmagem de um filme cômico (área 4); e existem trabalhos que se misturam com o estudo, como o de uma equipe de cientistas realizando um experimento (área 5). Contudo, a plenitude da atividade humana é alcançada somente quando nela coincidem, se acumulam, se exaltam e se mesclam trabalho, estudo e jogo (área 7). (DE MASI, 2000, p.147)

Além de apontar essa relação em função do trabalho, o autor ainda estende a ideia para uma perspectiva do trabalhador. Por exemplo, este, além de um trabalho concentrado na área 1, durante seu tempo livre voltado para o jogo ou o estudo (áreas 2 e 3) pode exercer outra atividade remunerada, como um caixa de banco que em casa administra um blog famoso e é remunerado por um portal de internet. Portanto, o profissional pode desenvolver convergências entre as suas atividades, melhorando sua atuação numa área específica a partir do momento em que concentra sua atenção em outras duas correlatas.

Deve ser assinalado que o ócio criativo pode desvirtuar-se em apropriação do tempo de lazer para fins utilitários. Visando especialmente seu potencial criativo, e sob o argumento do interesse pessoal do trabalhador, os discursos e práticas organizacionais podem operar no sentido de manter os indivíduos voltados para os imperativos da produção. Com essa ressalva, destaca-se que a proposta refere-se a um envolvimento com o trabalho, por parte dos indivíduos, além das exigências de um desempenho profissional marcado pela separação entre trabalho e outras dimensões da vida.

\section{Metodologia}

Esta pesquisa foi de cunho exploratório e adotou abordagem qualitativa. Os meios de coleta de evidências utilizados foram: a) entrevistas pessoais em profundidade com seis editores responsáveis por seis editoras; b) observação direta, pois as entrevistas foram realizadas nos escritórios e lojas das editoras; e c) documental, nos sites de comunidades de consumidores dos produtos das editoras. Os dados coletados foram analisados 
de forma interpretativa, através da triangulação das evidências obtidas. A pesquisa buscou identificar padrões em comum (teletrabalho e ócio criativo) e diferentes (casos de sucesso onde esses dois conceitos foram explorados, por vezes, valendo-se das comunidades virtuais de prática). Do referencial, espera-se que o fenômeno da relação teletrabalho/ócio criativo seja encontrado nas editoras (replicação literal) e o das comunidades virtuais de prática, em algumas destas (replicação teórica), uma vez que nem todas trabalhariam com esse tipo de relação.

Nas seis entrevistas, divididas em uma parte estruturada e noutra semiestruturada, realizadas entre agosto de 2007 e dezembro de 2008, desde o primeiro contato deixava-se claro que o assunto discutido tratava de práticas gerenciais relacionadas ao trabalho a distância, algo que a experiência dos editores poderia ajudar a transferir para a realidade de outras indústrias criativas. Fez-se uso da entrevista pessoal em profundidade com os seis entrevistados. Esse tipo de coleta foi escolhido por: a) enfocar diretamente o tópico do estudo de caso, b) permitir ao pesquisador conhecer uma parte do espaço de trabalho do entrevistado, e c) obter inferências causais percebidas (YIN, 2005). O tipo de entrevista foi o focado, pois esses encontros eram relativamente breves. Quando os entrevistados percebiam que o estudo buscava apenas coletar informações sobre alguns aspectos de sua rotina, as respostas eram cordiais e atenciosas, seja pelo fato de o assunto tratado não envolver nenhum segredo revelador, quanto pelo fato de o entrevistador ser um professor, a quem os editores sempre tratam como um possível parceiro.

Para a pesquisa foram identificadas 55 editoras que possuem publicações voltadas para o público infantojuvenil, todas elas encontradas em estandes de venda em um ou mais dos seguintes eventos: Bienal do Livro-RJ/2007, Libre - Primavera dos Livros-RJ/2007 e Encontro Internacional de RPG-SP/2007. Dentre as 22 editoras que responderam a um primeiro contato por telefone ou e-mail, seis foram escolhidas para a pesquisa, utilizando-se como parâmetro aquelas que informaram experiências de sucesso relacionadas aos conceitos pesquisados e/ou aquelas que, de alguma maneira, puderam oferecer alguma experiência relevante. Foram feitas duas entrevistas no Rio de Janeiro, duas em São Paulo e duas em Juiz de Fora. As editoras pesquisadas foram:

- Editora A, de Juiz de Fora, MG - trabalha com tiragens pequenas (aproximadamente 1.000 livros). Apesar de pequena e distante dos maiores centros, possui considerável público e número significativo de parceiros comerciais em diversos locais do país;

- Editora B, de São Paulo, SP - vale-se de tiragens pequenas e médias (de 1.000 a 3.000 livros). Trabalha com diversas pequenas comunidades para microtiragens, produzidas e divulgadas por esses parceiros comerciais;

- Editora C, de São Paulo, SP - só trabalha com tiragens grandes (5.000 livros ou mais). Trata-se de empresa grande e forte no mercado, que se vale do teletrabalho autônomo com autores, ilustradores, desenhistas, revisores e diagramadores. Trabalha não só com livros, mas também com cards e miniaturas;

- Editora D, do Rio de Janeiro, RJ - trabalha apenas com tiragens grandes (5.000 livros ou mais). Recorre ao teletrabalho autônomo de autores, ilustradores, desenhistas, revisores e diagramadores;

- Editora E, do Rio de Janeiro, RJ - trabalha com tiragens médias ou grandes (3.000 livros ou mais). É ao mesmo tempo editora, agência de comunicação e livraria, o que leva a entender que pelo menos o dono se vale do teletrabalho e do ócio criativo;

- Editora F, de Juiz de Fora, MG - trabalha com tiragens pequenas (cerca de 1.000 unidades), comporta um portal de internet que movimenta cerca de 5.000 visitas diárias de jovens e movimenta um site sustentado por fãs que trabalham em troca do status de fazer parte da sua equipe. 


\section{Resultados}

Todas as editoras pesquisadas fazem uso intensivo das TICs para organizar o trabalho e alavancar seus negócios. A oferta de livros on-line, eliminando o intermediário em parte das vendas, é explorada por todas elas.

O que mais chama a atenção nas evidências colhidas é o envolvimento direto do público com os produtos oferecidos. Os fãs formam comunidades de relacionamento na internet, articuladas principalmente a partir de uma identidade constituída no consumo dos produtos. Essas comunidades sustentam e contribuem para o aprimoramento da produção, tendo como referência seus próprios valores existenciais e estéticos, o que ilustra o caráter cultural do consumo de livros.

A força dessas comunidades pode ser sentida especialmente no caso das editoras pequenas, que delas dependem para sobreviver. É o caso da Editora B, que, com suas microtiragens, passou a buscar pequenas comunidades virtuais para oferecer uma oportunidade de escrever suas publicações em parceria, desde que se comprometessem a ajudar a vender todas as 200 ou 250 unidades daquela edição. Com cerca de oito títulos publicados dessa forma, os editores dividem boa parte de seu esforço com esses parceiros comerciais, que, mesmo realizando um trabalho não profissional, conseguem garantir suas vendas e algum lucro.

A relação entre essas comunidades e as editoras é, de certa forma, simbiótica, uma vez que ambas as partes têm interesse na continuidade da relação - de um lado, para sobrevivência comercial, e de outro, para sustentação identitária. Assim, se por um lado as editoras tiram partido da força de trabalho desses fãs, sem retorno financeiro, por outro, pode-se dizer que o envolvimento com o processo produtivo é feito de forma consentida e engajada e que o retorno esperado é de ordem subjetiva.

As editoras tomam uma série de iniciativas para fomentar os laços com as comunidades de fãs:

- a Editora C promove eventos de role-playing games (RPG) para vender seus livros e se junta a organizações de fãs para promover campeonatos de seus card games;

- a Editora F publica resenhas de livros de diferentes editoras em seu portal, além de divulgar algumas linhas em seus fóruns de discussão;

- as editoras A, B e F exploram, ao lado de parceiros comerciais conquistados no ciberespaço, o contato com diversas comunidades virtuais, que ajudam na divulgação e aliviam as editoras para trabalhar com outras publicações, às vezes, com as mesmas características.

No caso da Editora F, a comunidade que orbita em volta de seu portal existe em todas as dimensões previstas por Wenger (1998) para as comunidades de prática: engajamento mútuo, graças à participação ativa de muitos de seus membros em favor do hobby do RPG, mesmo que ele esteja segmentado em diferentes títulos; empreendimento conjunto, pois o desenvolvimento de projetos e ideias é feito por grupos que utilizam o fórum do portal como ponto de encontro; e repertório compartilhado, já que todo o conteúdo da editora $\mathrm{F}$ é gratuito. Dos possíveis indicadores de que uma comunidade de prática se formou, o portal apresenta todos:

- relações mútuas sustentadas;

- identidades definidas mutuamente;

- maneiras compartilhadas de engajamento para fazer coisas juntos;

- facilidade para acessar de maneira apropriada ações e produtos;

- rápido fluxo de informações e propagação de inovações; 
- $\quad$ uso de ferramentas, representações e outros artefatos específicos;

- ausência de comentários introdutórios, como se as conversas e interações fossem a continuação de um processo em curso;

- histórias locais compartilhadas, como piadas internas;

- $\quad$ rápida exposição de um problema a ser discutido;

- $\quad$ emprego de jargões e expressões na sua comunicação;

- coincidência substancial em como os participantes descrevem sua pertença à comunidade;

- $\quad$ estilos reconhecidos de que alguém é membro da comunidade; $\mathrm{e}$

- um discurso comum refletindo certa perspectiva de mundo.

Outras relações podem estar no caminho da formação de comunidades de prática, como os autores e ilustradores que se reúnem na loja da Editora A, as comunidades virtuais que a Editora B publica e as listas de prestadores de serviço da Editora D. No entanto, todas elas estão ainda muito distantes do crescimento e do amadurecimento alcançado pelo portal da Editora F.

Os resultados da pesquisa indicam que, quando se trata de serviço autônomo no mercado editorial, teletrabalho e ócio criativo caminham juntos, tanto na realidade do trabalho mal remunerado (caso de alguns revisores e ilustradores) quanto nas parcerias comerciais (como as que ocorrem com autores famosos). No entanto, no caso da contratação mal remunerada, deve-se esperar que os melhores profissionais não estejam disponíveis. Nesse caso, é comum recorrer a organizações que possam fornecer mão de obra facilmente, como acontece nas comunidades virtuais, mas também nas faculdades e seus escritórios-modelos, que procuram enquadrar seus alunos em atividades minimamente relacionadas àquilo com que desejam trabalhar no futuro. Mesmo que esses prestadores de serviços possam ter a qualidade de seus trabalhos contestada, é indiscutível a sua utilidade quando são aproveitados para oferecer suporte aos profissionais cuja eficiência e responsabilidades sejam maiores.

Os resultados desta pesquisa indicam que não se sustenta a noção de que o teletrabalho exija menos do teletrabalhador do que o trabalho no escritório (DE MASI, 1999, 2000), especialmente, quando o telempregador compensa a insegurança pela falta de controle direto com um volume de trabalho maior. Os resultados vão ao encontro de outros estudos que apontam que a flexibilidade do teletrabalhador se dá pela possibilidade de este decidir quando vai trabalhar, se de manhã, à tarde, à noite ou de madrugada (COSTA, 2003; PUMA; WETZEL, 2007; TIETZE, 2002). É preciso destacar também que, para o empregador, a flexibilidade diz respeito à possibilidade de fugir das exigências que o direito trabalhista o obriga a atender, como, por exemplo, o limite diário de trabalho de oito horas e a remuneração pelo trabalho realizado aos domingos e feriados.

De acordo com alguns estudos (COSTA, 2003; PUMA; WETZEL, 2007; WINTER, 2005), o empregador força o trabalho na vida pessoal do teletrabalhador. No entanto, quando é a vida pessoal que entra no trabalho, como acontece com os fãs que escrevem e lançam livros de ficção, o teletrabalho não pode ser visto como forma de exploração dos prestadores de serviço. Muitos desses fãs não são trabalhadores ou prestadores de serviço, mas parceiros comerciais das editoras, cujas obras são oferecidas e não, exigidas, nessa relação de trabalho peculiar.

Mesmo dentro do mercado editorial, quanto maior a empresa, mais restritas ficam as possibilidades de exploração do ócio criativo, por duas razões: a) empresas de grande porte contratam mais trabalhadores, tenham eles vínculo empregatício ou sejam prestadores de serviços. Por essa razão, precisam definir com maior precisão o serviço requisitado para que seja remunerado apropriadamente; logo, não podem exigir o 
tempo de estudo e jogo sem compensar financeiramente o trabalhador por esse "serviço adicional"; e b) à medida que a empresa cresce e precisa se estruturar, não tem condições de contratar apenas pessoas que gostam daquele trabalho e que se dedicam mesmo quando poderiam estar fazendo outras coisas. Precisa contratar pessoas com a capacitação mais apropriada, mesmo que não levem o trabalho para seu tempo livre. Quando uma empresa é pequena, os envolvidos sabem das limitações e sabem haver pouco espaço para cobrar dela qualquer esforço adicional.

Apesar de sua aplicação mais restrita, o ócio criativo pode fazer com que uma empresa produza mais com o mesmo número de membros numa equipe. No mínimo, o empresário irá concordar que os profissionais que se envolvem mais nos seus projetos têm uma capacidade muito maior de atender à demanda do serviço que aqueles que mal aguentam esperar pela hora de irem para casa. Por outro lado, quando o negócio não envolve uma atenção tão constante quanto a que existe dentro do escritório e o trabalho levanta o interesse por parte do público, não há dúvidas de que será possível aumentar consideravelmente a sua produtividade se forem empregadas pessoas que trazem esse produto para suas casas, se não fisicamente, pelo menos dentro de suas cabeças. Mesmo que um envolvimento mais passional possa interferir prejudicialmente nas relações de trabalho e na visão do negócio por parte do empregado, a sua dedicação poderá compensar todas essas desvantagens, desde que toda a equipe não tenha o mesmo tipo de envolvimento.

No entanto, só poderá compreender plenamente as vantagens do ócio criativo aquele que perceber que, na maior parte das vezes, esse conceito oferece mais espaço ao empregador e a seus parceiros comerciais do que para os trabalhadores - sejam eles autônomos ou não. No caso da pesquisa, os autores e artistas que se valem da convergência de atenções do trabalho-estudo-jogo não são funcionários ou subalternos, mas parceiros comerciais que veem o mercado muito mais como um editor do que como um revisor ou um diagramador.

\section{Conclusões}

Este estudo teve como objetivo explorar as relações de trabalho presentes nas editoras voltadas para o publico infantojuvenil, entendidas relações de trabalho como aquelas referentes a questões organizativas e a relações pessoais com o trabalho. Foi observado que as editoras há muito se apoiam em práticas flexíveis de organização do trabalho, especialmente, o trabalho a distância, contratado sob demanda para a produção de determinada publicação. Ao mesmo tempo, por serem indústrias criativas, seus recursos críticos encontramse incorporados a indivíduos, sobre os quais podem exercer controle limitado. O sucesso dependerá, em última instância, da intensidade e da qualidade do envolvimento dos participantes com o projeto, exigindo uma relação significativa com o trabalho.

Os resultados da pesquisa aqui relatada indicam que as práticas de gestão adequadas envolvem não só flexibilidade organizativa, mas principalmente um entendimento ampliado do processo de produção e de consumo do bem cultural (livro), que passa pela integração de editores, autores e consumidores via formação de comunidades virtuais atuando de forma simbiótica.

A criação e a manutenção de comunidades de consumidores fãs dos produtos das editoras podem significar, em alguns casos, a própria viabilidade das empresas. Essas comunidades representam não apenas um público consumidor cativo, mas também força de trabalho não remunerada para as editoras. Ao mesmo tempo, o consumo dos livros tem um caráter de sustentação e reforço identitário dos consumidores que participam dessas comunidades. As editoras reforçam essa ligação pela adequação dos produtos aos requisitos (que, por sua vez, refletem os valores dos consumidores) dessas comunidades.

A adoção do teletrabalho é extensiva, especialmente, por envolver trabalhadores autônomos, parceiros comerciais e, em alguns casos, colaboradores que sequer buscam compensação financeira. Quanto ao envolvimento pessoal com o trabalho, observou-se que os editores percebem que o ócio criativo retrata uma 
relação característica daquela mantida por autores e artistas que se valem da convergência de atenções do trabalho-estudo-jogo, mas diversa da estabelecida por trabalhadores subalternos.

Na sociedade contemporânea, o consumo de bens não culturais assume características de consumo cultural, enquanto o envolvimento dos consumidores no processo produtivo vem ganhando espaço. A pesquisa mostra que, em certos nichos, a própria existência do produto (publicação) só se sustenta como projeto da comunidade que o produz/consome. A gestão das editoras, com a flexibilização organizativa e com a exploração dos vínculos subjetivos com o trabalho e com o consumo, estende as relações produtivas além de vínculos contratuais formais, capitalizando o tempo livre, a disponibilidade de cada um e a identidade de empregados, de contratados e, mesmo, dos consumidores. A experiência dessas organizações pode vir a estimular as demais, desafiadas a explorar as possibilidades tecnológicas e a responder às mudanças no contrato psicológico de trabalho e na natureza do consumo.

\section{Referências}

BENDASSOLI, P. F. et al. Indústrias criativas: definição, limites e possibilidades. RAE, v. 49, n .1, p. 10-18, 2009.

CAVES, R. E. Creative industries: contracts between art and commerce. Cambridge, MA: Harvard University Press, 2000.

COSTA, I. S. A. Poder/saber e subjetividade na construção do sentido do teletrabalho. Tese de doutorado (Administração) - Escola Brasileira de Administração Pública de Empresas (Ebape)/Fundação Getúlio Vargas (FGV), Rio de Janeiro, 2003.

Teletrabalho: subjugação e construção de subjetividades. RAP, v. 41, n. 1, p. 105-124, 2007.

DE MASI, D. O futuro do trabalho: fadiga e ócio na sociedade pós-industrial. Rio de Janeiro: José Olympio; Brasília: Ed. UnB, 1999.

O ócio criativo. Rio de Janeiro: Sextante, 2000.

DOHERTY, S.; ANDREY, J.; JOHNSON, L. The economic and social impacts of telework. In: Telework and the new workplace of the $21^{\text {st }}$ century. Washington: Department of Labor, 2000.

FLORIDA, R. The rise of the creative class. New York: Basic Books, 2004.

HARVEY, D. Condição pós-moderna: uma pesquisa sobre as origens da mudança cultural. 12.ed. São Paulo: Loyola, 2003.

HASEMAN, B. Creative practices. In: HARTLEY, J. Creative industries. Carlton, Australia: Blackwell, 2005.

JAGUARIBE, A. As indústrias criativas: parâmetros para as políticas públicas. Apresentado no workshop da Unctad sobre as Indústrias Criativas Empreendedoras. São Paulo, 2004.

LAMPEL, J.; LANT, T.; SHAMSIE, J. Equilíbrio em cena: o que aprender com as práticas organizacionais das indústrias culturais. RAE, v. 49, n. 1, p. 19-26, 2009.

LESSER, E. L.; STORCK, J. Communities of practice and organizational performance. IBM Systems Journal, v. 40, n. 4, p. 831-841, 2001.

NILLES, J. Making telecommuting happens. EUA: Lexington, 1994. 
OUTWAITE, W.; BOTTOMORE, T. Dicionário do pensamento social do séc. XX. Rio de Janeiro: Jorge Zahar, 1996.

PUMA, M.; WETZEL, U. Trabalho em transformação: dimensões de espaço e tempo trabalhando em casa. In: ENCONTRO NACIONAL DOS PROGRAMAS DE PÓS-GRADUAÇÃO DE ADMINISTRAÇÃO, 31., Rio de Janeiro. Anais...: Rio de Janeiro, ANPAD, 2007.

QVORTUP, L. Teleworks: visions, definitions, realities, barriers. Paris: OECD, 1992.

ROBINSON, K. Balancing the books. In: HARTLEY, J. (Ed.). Creative industries. Carlton, Australia: Blackwell, 2005 .

SENGE, P. M. A quinta disciplina. São Paulo: Best Seller, 2001.

TEIXEIRA FILHO, J. Comunidades virtuais: como as comunidades de prática na internet estão mudando os negócios. Rio de Janeiro: Senac, 2002.

TIETZE, S. When "work" comes "home": copying strategies of teleworkers and their families. Journal of Business Ethics, v. 41, n. 4, p. 37-42, 2002.

TROPE, A. Organização virtual: impactos do teletrabalho nas organizações. Rio de Janeiro: Qualitymark, 1999.

UNESCO. Understanding creative industries: statistics for public-policy making. 2006. Disponível em: <http://portal.unesco.org/culture/en/files/30297/11942616973cultural_stat_EN.pdf/cultural_stat_EN.pdf>. Acesso em: 4 jan. 2010.

WENGER, E. Communities of practice: learning, meaning and identity. New York: Cambridge University Press, 1998.

School Press, 2002.

; McDERMOTT, R.; SNYDER, W. M. Cultivating communities of practice. Boston: Harvard Business

WINTER, V. R. L. Teletrabalho: uma forma alternativa de emprego. São Paulo: LTr, 2005.

YIN, R. K. Estudo de caso. 3. ed. Porto Alegre: Bookman Artmed, 2005.

\footnotetext{
A distinção entre as pequenas e as grandes editoras reside na quantidade de unidades produzidas. No Brasil, uma publicação de tiragem pequena tem entre mil e 3 mil cópias, o suficiente para fazer uma distribuição razoável nas livrarias dos maiores centros urbanos do país. De 3 mil a 5 mil cópias, além do contato com as livrarias, já é possível fazer uma distribuição setorizada pelas bancas de jornal - as cópias são distribuídas em um estado e recolhidas um mês depois para serem redistribuídas em outro. A partir de 5 mil cópias, as grandes tiragens são facilmente distribuídas nas bancas e livrarias, além de possuírem um custo por unidade bastante competitivo. As grandes editoras se concentram neste tipo de tiragem, que dificilmente ultrapassa 10 mil cópias. Editoras menores costumam ficar restritas a tiragens pequenas, não só por falta de capital de giro, mas também porque o público que consome certos tipos de literatura é reduzido, ainda que fiel. Quanto maior o potencial financeiro e profissional da editora, mais ela pode arcar com os custos de tiragens médias ou grandes, embora, sempre limitada pelo poder de compra de cada público, pois há quem lucre a partir de múltiplas tiragens menores de dezenas de títulos. Independente do tamanho, o lucro das editoras está ligado a uma tiragem grande o bastante para alcançar a maior área de distribuição possível e pequena o suficiente para ter um mínimo de encalhe. No caso brasileiro, deve-se destacar o papel da isenção de impostos, no âmbito da Lei de Incentivo à Cultura, para tornar livros e revistas um bom negócio para empresas pequenas.
} 